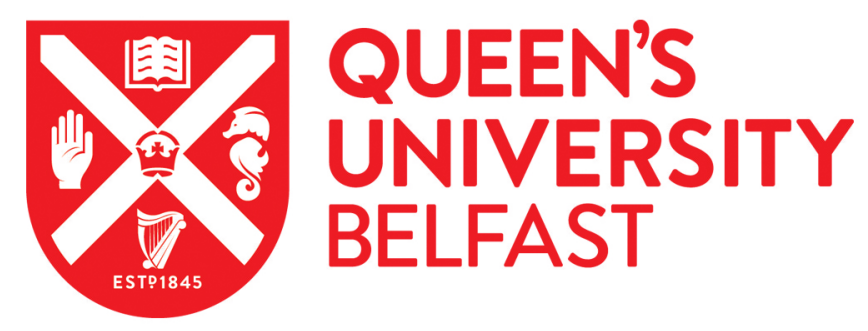

\title{
Extensive Sequential Polymorphic Interconversion in the Solid State: Two Hydrates and Ten Anhydrous Phases of Hexamidine \\ Diisethionate
}

Edkins, K., Mclntyre, G. J., Wilkinson, C., Kahlenberg, V., Toebbens, D., Griesser, U. J., Bruening, J., Schmidt, M. U., \& Steed, J. W. (2019). Extensive Sequential Polymorphic Interconversion in the Solid State: Two Hydrates and Ten Anhydrous Phases of Hexamidine Diisethionate. Crystal Growth and Design. https://doi.org/10.1021/acs.cgd.9b01170

Published in:

Crystal Growth and Design

Document Version:

Peer reviewed version

Queen's University Belfast - Research Portal:

Link to publication record in Queen's University Belfast Research Portal

\section{Publisher rights}

Copyright $\odot 2019$ American Chemical Society.This work is made available online in accordance with the publisher's policies. Please refer to any applicable terms of use of the publisher.

\section{General rights}

Copyright for the publications made accessible via the Queen's University Belfast Research Portal is retained by the author(s) and / or other copyright owners and it is a condition of accessing these publications that users recognise and abide by the legal requirements associated with these rights.

Take down policy

The Research Portal is Queen's institutional repository that provides access to Queen's research output. Every effort has been made to ensure that content in the Research Portal does not infringe any person's rights, or applicable UK laws. If you discover content in the Research Portal that you believe breaches copyright or violates any law, please contact openaccess@qub.ac.uk. 


\title{
Extensive sequential polymorphic interconversion in
}

\author{
the solid-state: two hydrates and ten anhydrous
}

\section{phases of hexamidine diisethionate}

Katharina Edkins, ${ }^{* a}$ Garry J. McIntyre, ${ }^{b \$}$ Clive Wilkinson, ${ }^{b \dagger}$ Volker Kahlenberg, ${ }^{c}$ Daniel Többens, ${ }^{c \$}$ Ulrich J. Griesser, ${ }^{c}$ Jürgen Brüning, ${ }^{d}$ Martin U. Schmidt ${ }^{d}$ Jonathan W. Steed ${ }^{e}$ a School of Pharmacy, Queen's University Belfast, 97 Lisburn Road, Belfast BT9 7BL, UK b Institut Laue-Langevin, 71 Rue des Martyrs, 38042 Grenoble, France c Institut für Mineralogie and Petrographie and Institut für Pharmazie, Leopold Franzens Universität Innsbruck, Innrain 52 and 52c, 6020 Innsbruck, Austria d Johann Wolfgang Goethe Universität Frankfurt, Max-von-Laue-Str 7, 60438 Frankfurt am Main, Germany e Department of Chemistry, Durham University, South Road, Durham DH1 3LE, UK

ABSTRACT. Crystal polymorphism and solvent inclusion is a dominant research area in the pharmaceutical industry and continues to unveil complex systems. Here, we present the solid-state system of hexamidine diisethionate (HDI), an antiseptic drug compound forming a dimorphic dihydrate as well as ten anhydrous polymorphs. The X-ray and neutron crystal structures of the hydrated crystal forms and related interaction energies show no direct interaction between the 
cation and water but very strong interactions between cation and anion, and anion and water. This is observed macroscopically as high stability of the hydrate against dehydration by temperature and humidity. The anhydrous polymorphs reveal a rare case of sequential and reversible polymorphic transformations, which are characterized by thermal analysis and variabletemperature powder X-ray diffraction (PXRD). While most transitions are accompanied by significant structural changes, the low-energy transitions can only be detected as slight changes in the reflection positions with temperature. HDI thus represents a model compound to investigate polymorphic transitions with small structural changes.

\section{Introduction}

The ability of organic molecules to arrange in different crystal packing patterns, i.e. crystal polymorphism, has attracted the scientific community since its first description in the early $19^{\text {th }}$

Century. ${ }^{1}$ Different molecular packing can influence the physicochemical characteristics of a material, such as its melting point, solubility, hardness and conductivity, giving crystal polymorphism impact on various fields of material science ranging from pharmaceuticals to thinfilm applications for organic light-emitting devices. In addition to altered behavior, particular crystal forms are only stable within a limited temperature and pressure range, outside which they become metastable and will potentially transform into a more stable polymorph. ${ }^{2,3}$ Since polymorphic transitions can be either reversible (enantiotropic) or irreversible (monotropic), knowledge about the stability range of each crystal form is essential for any application. This is especially true for the pharmaceutical industry, ${ }^{4}$ as transitions can occur during the manufacturing of the raw materials, best showcased by the infamous ritonavir case, ${ }^{5-7}$ but also in the later stages of formulation or even in the final medicine, as occurred in rotigotine transdermal patches. ${ }^{8}$ 
In order to better understand crystal polymorphism, compounds with multiple crystal forms are of enduring interest. Arguably the best known of these model compounds is 5-methyl-2-[(2nitrophenyl)amino]-3-thiophene carbonitrile, or ROY, named after its red, orange and yellow colored crystal forms. Currently, 11 anhydrous crystal forms have been observed with ten of them structurally characterized, which gives a rare insight into the different crystal packing motifs. ${ }^{9}, 10$ All of these crystal forms can be directly crystallized either from solution or from the melt and occur either as pure phases or concomitantly. This behavior has been exploited to investigate the influence of the crystallization environment, ${ }^{11}$ or that of isotopic exchange on concomitant crystallization. ${ }^{12}$ In addition to experimental studies, the structural diversity of ROY enables the testing of crystal structure prediction algorithms against this complex system and further honing of computational ability. ${ }^{13-15}$ The polymorphism of aripiprazole is another example of the high number of anhydrous crystal forms being formed, in this case in an active pharmaceutical ingredient. To date, 12 anhydrous crystal forms have been described, of which nine have been structurally characterised. ${ }^{16-18}$ Like ROY, all of these polymorphs can be crystallized directly from solution or the melt. Polymorphic interconversion, i.e. transition from one solid form to a more stable one, is hindered in this system, and only the transformation of form X to form I has been observed. ${ }^{17}$ Better model compounds for polymorphic transitions are found in the class of the barbitals, e.g. barbital itself which exists as six polymorphs, ${ }^{19}$ and phenobarbital with 11 anhydrous crystal forms. $^{20,21}$ These systems show both solid-to-solid phase transitions as well as melting and recrystallisation of the respective polymorphs upon heating. However, sequential polymorphic transitions are still rare, and in most cases a full characterization in terms of thermal behavior as well as structural data is lacking. 
An alternative way to obtain new anhydrous crystal forms is by desolvation of solvated crystal forms, as particular packing motifs are stabilized through solvent inclusion and retained through this transition. While ROY does not show solvent inclusion, aripiprazole has been crystallized as several solvates, all of which desolvate to the known crystal form III. $^{22}$ Very recently, $R$ encenicline hydrochloride has been reported as an impressive model system for solvate formation and the discovery of novel forms through desolvation. ${ }^{23}$ In fact, this route has led to the discovery of 11 of the 12 anhydrous crystal forms, of which ten crystal structures could be determined. Only one anhydrous polymorph can be obtained from solution through direct crystallization, and the same polymorph is the product of any thermal phase transition of the other polymorphs. Very recently, this behavior has also been shown for galunisertib, a prolific solvate former, for which ten polymorphs have been obtained mainly through desolvation. ${ }^{24}$

On the other hand, solvates, and especially hydrates containing water from crystallization, pose particular problems in the pharmaceutical industry. Solvates are generally used to purify products during synthesis and manufacture but give rise to the danger of carrying over potentially harmful solvent into the final medicine. The use of solvates and solvents in the pharmaceutical industry is thus highly regulated. ${ }^{25}$ Since water is non-toxic, hydrated crystal forms are less harmful for production. However, due to their thermodynamic stability in water, they show the lowest solubility in this solvent and thus need special care to enable dissolution when applied to the patient. ${ }^{26}$ Like anhydrous polymorphs, hydrates are stable only in a specific temperature and pressure window, with an added variable of stability in altered relative humidity (RH) environments. In addition, the stoichiometry of hydrates can vary, not only between different compounds, but also between different hydrates of the same compound. We could recently show this behavior for the X-ray contrast agent diatrizoic acid and its sodium salt, which both show 
multiple hydrates (up to the octahydrate for the sodium salt) and interconversion depending on $\mathrm{RH}^{27,28}$ It is also not quite clear yet, what the role of the water molecules is in the crystal structure, i.e. whether it is fulfilling a purely space-filling role or if it is structure-forming. We investigated this problem by using X-ray and neutron single-crystal diffraction and used empirical crystal lattice energy calculations to deconvolute the strong molecular interactions within the hydrated crystal structure. Using this approach we could explain the existence of a water molecule within the cavity of a calix[4]arene host, ${ }^{29}$ the close relationship between theophylline hydrate and dehydrate,${ }^{30}$ and the surprising cracking and recovery of single crystals of piroxicam monohydrate at lowtemperatures. ${ }^{31}$

In this current study, we present the surprisingly complex solid-state system of the antiseptic hexamidine diisethionate (HDI, scheme 1) in terms of hydrate formation, anhydrous polymorphs and sequential phase transitions.<smiles>N=C([NH3+])c1ccc(OCCCCCCOc2ccc(C(=[NH2+])[NH3+])cc2)cc1</smiles>

Scheme 1. Chemical structure of hexamidine diisethionate.

\section{Materials and Methods}

Materials 
Hexamidine diisethionate was kindly donated by Sanofi-Aventis (Frankfurt, Germany). The substance was purified by recrystallization from deionized water before use.

Methods

Optical polarized light and hot-stage microscopy (HSM): Microscopic observations were performed with an Olympus BH-2 polarized light microscope (Olympus Optical GmbH, Vienna, Austria) equipped with a polarizer and a rotatable analyzer. For thermo-microscopic investigations, the microscope was equipped with a Kofler hot stage (Reichert Thermovar, Vienna, Austria). Photomicrographs were taken using an Olympus DP50 microscope stage digital camera with a resolution of 5.8 million pixels, operated through the AnalySIS 3.2 software (Soft Imaging System GmbH, Hamburg, Germany).

Differential scanning calorimetry: DSC measurements were conducted using a Diamond HyperDSC (Perkin Elmer, Norwalk, Ct, USA) equipped with a Controlled Cooling Accessory CCA 7 and operated with Pyris 7.0 software. Samples of 1 to $3 \mathrm{mg}$ were accurately weighed ( $\pm 0.0005 \mathrm{mg}$ ) into sealed (anhydrous crystal forms) or pin-holed (dihydrates) Al-pans (30 $\mu \mathrm{L})$ on a UM3 ultramicrobalance (Mettler, Greifensee, Switzerland), and scanned between -100 to 230 ${ }^{\circ} \mathrm{C}$ at a heating rate of $10 \mathrm{~K} / \mathrm{min}$. The instrument was purged with dry helium for measurements in the range from -100 to $100^{\circ} \mathrm{C}$ and dry nitrogen for those in the range from -20 to $230{ }^{\circ} \mathrm{C}$, both gases at a purging rate of $20 \mathrm{~mL} / \mathrm{min}$ and maximum water content of $5 \mathrm{ppm}$. Temperature calibration was performed with cyclohexane (m.p. $-87.06{ }^{\circ} \mathrm{C}$ ), $n$-decane (m.p. $-28.0{ }^{\circ} \mathrm{C}$ ) and benzophenone (m.p. $48.0^{\circ} \mathrm{C}$ ) in the case of helium purge, and benzophenone (m.p. $48.0^{\circ} \mathrm{C}$ ) and caffeine (m.p. $236.2^{\circ} \mathrm{C}$ ) in the case of nitrogen purge. The energy calibration was performed with pure indium (purity $99.999 \%$, m.p. $156.6{ }^{\circ} \mathrm{C}$, heat of fusion $28.45 \mathrm{~J} / \mathrm{g}$ ). 
Thermogravimetric analysis (TGA): TGA curves were recorded using a TGA7 thermogravimetric system (Perkin-Elmer, Norwalk, Ct., USA) operated with Pyris 2.0 software. Samples of approximately $2-6 \mathrm{mg}$ were accurately weighed $( \pm 0.0005 \mathrm{mg})$ into $50 \mu \mathrm{L}$ platinum pans and subjected to non-isothermal TGA at a heating rate of $10 \mathrm{~K} / \mathrm{min}$ in a temperature range from 25 to $220^{\circ} \mathrm{C}$. Nitrogen was used as a purge gas (balance purge: $50 \mathrm{~mL} / \mathrm{min}$, sample purge: $25 \mathrm{~mL} / \mathrm{min})$.

Moisture sorption/desorption experiments: Dynamic moisture sorption and desorption were determined gravimetrically at $25^{\circ} \mathrm{C}$ using an automatic multi-sample moisture sorption analyzer (SPS11, Projekt-Meßtechnik, Ulm, Germany). Approximately $1.0 \mathrm{~g}$ of accurately weighed crystals (balance resolution: $10 \mu \mathrm{g}$ ) were placed in an aluminium sample dish (diameter: $5 \mathrm{~cm}$ ), transferred into the sample compartment of the moisture sorption analyzer, and equilibrated at $0 \% \mathrm{RH}$. The RH was cycled in $10 \%$ steps up to $90 \% \mathrm{RH}$ and back down to $0 \% \mathrm{RH}$. The mass change of the material was recorded every 8 min with the equilibrium condition set to $<0.001 \%$ within 35 minutes and the maximum residence time to 24 hours for each RH level. The mass change at each RH step was used to draw the moisture sorption isotherms.

Powder and single-crystal X-ray diffraction: Powder X-ray diffraction data for phase characterization were collected on a Stoe STADI MP diffractometer in bisecting flat-plate transmission geometry. The diffractometer is equipped with an asymmetric primary beam $\mathrm{Ge}(111)$ monochromator (yielding strictly monochromatic $\mathrm{Cu}-\mathrm{K}_{\alpha 1}$ radiation) and a linear position sensitive detector with $4^{\circ}$ detector range. In transmission geometry the axial beam width was set to $2 \mathrm{~mm}$. The samples were prepared in quartz glass capillaries of $0.7 \mathrm{~mm}$ in diameter and placed in a STOE 0.65.LT furnace. Forms $\mathrm{A}$ and $\mathrm{B}$ as well as the dihydrate were measured at room temperature. Forms $\mathrm{H}$, I and $\mathrm{J}$ were measured at 70,30 and $-30{ }^{\circ} \mathrm{C}$, respectively. The temperature-controlled 
measurement of the remaining crystal forms was started at $25^{\circ} \mathrm{C}$ and the temperature raised in 5 ${ }^{\circ} \mathrm{C}$ steps up to $100{ }^{\circ} \mathrm{C}$, then in $10{ }^{\circ} \mathrm{C}$ steps to $180^{\circ} \mathrm{C}$. Subsequently, the temperature was decreased in $20^{\circ} \mathrm{C}$ steps to $100{ }^{\circ} \mathrm{C}$ and further to $25^{\circ} \mathrm{C}$ in $5^{\circ} \mathrm{C}$ steps. The data collection was started 2 min after the respective temperature was reached, and each temperature step was measured for $1 \mathrm{~h}$. The absolute accuracy of the temperatures is $\pm 1{ }^{\circ} \mathrm{C}$, temperature stability is $\pm 0.3{ }^{\circ} \mathrm{C}$ and total temperature gradient over the length of the sample is $<1{ }^{\circ} \mathrm{C}$.

The crystal structure of polymorph B was determined from powder diffraction data measured carefully in the range from 2 to $80^{\circ} 2 \theta$. After indexing with DICVOL, the crystal structure was solved by the real-space method with simulated annealing using DASH. ${ }^{32}$ Subsequently, the structure was refined by Rietveld methods using TOPAS. ${ }^{33}$ All bond lengths, angles and planar groups were restrained.

Dihydrate single crystals of suitable size for structure determination by X-ray diffraction were obtained by evaporation of a water solution at room conditions. For the measurement, one of the crystals was soaked in perfluoropolyether-oil and measured at $173 \mathrm{~K}$ on a STOE IPDS-II diffractometer (Stoe \& Cie GmbH, Darmstadt, Germany) using Mo-Ka radiation. A second one was measured at room temperature. The structure solution and refinement were carried out using Olex2. ${ }^{34}$ All the $\mathrm{H}$ atom positions were generated using a riding model in idealized geometries and were refined isotropically.

Neutron single-crystal diffraction: A single crystal of the dihydrate of size $3 \times 1.5 \times 0.75 \mathrm{~mm}^{3}$ was mounted on a vanadium pin with vacuum grease and placed in a helium-flow cryostat on the Very-Intense Vertical-Axis Laue Diffractometer (VIVALDI) ${ }^{35,36}$ at the Institut Laue-Langevin, Grenoble, France. Data were collected from the stationary crystal at 290, 260 and $20 \mathrm{~K}$ using a white neutron beam with wavelengths between 0.8 and $5 \AA$. The crystal was rotated $20^{\circ}$ about an 
axis perpendicular to the incident neutron beam between Laue patterns, which were recorded in exposures of $90 \mathrm{~min}$. The patterns were indexed using the program LAUEGEN, ${ }^{37,38}$ and the reflections were integrated using the local program INTEGRATE $+{ }^{39}$ and normalized to a common incident wavelength using the program REARRANGE. Correction for absorption was deemed unnecessary in view of the small sample volume. The structures were refined against the obtained data set using SHELXL, ${ }^{40}$ starting with the structural model obtained by X-ray diffraction. All atoms were refined anisotropically.

\section{Results and discussion}

\section{Hydrates}

Crystallization of HDI from aqueous solution or the melt in the presence of moisture yields a hydrated crystal form. Upon heating, the block-shaped crystals undergo dehydration, which is observable as pseudomorphosis between 55 and $70{ }^{\circ} \mathrm{C}$ by HSM, and accompanied weight loss below $80{ }^{\circ} \mathrm{C}$ by TGA (Fig. 1). The total weight loss of $5.5 \%$ correlates well with the calculated value of $5.6 \%$ for a dihydrate. The DSC trace shows a broad dehydration endotherm in the range from 50 to $95{ }^{\circ} \mathrm{C}$ with a sharp shoulder between 95 and $100{ }^{\circ} \mathrm{C}$ with a peak at $96.23{ }^{\circ} \mathrm{C}$. This second endotherm corresponds to the melting of the intact hydrate. Upon further heating, the dehydrated crystal form undergoes a phase change between 170 and $180{ }^{\circ} \mathrm{C}$ before melting above $220^{\circ} \mathrm{C}$. Upon cooling from room temperature, this dihydrate undergoes a rare and reversible phase transition below $0{ }^{\circ} \mathrm{C}$ with a very low energy of $0.3 \mathrm{~kJ} / \mathrm{mol}$ (Fig. 1 insert) making the two dihydrates polymorphs enantiotropic. 


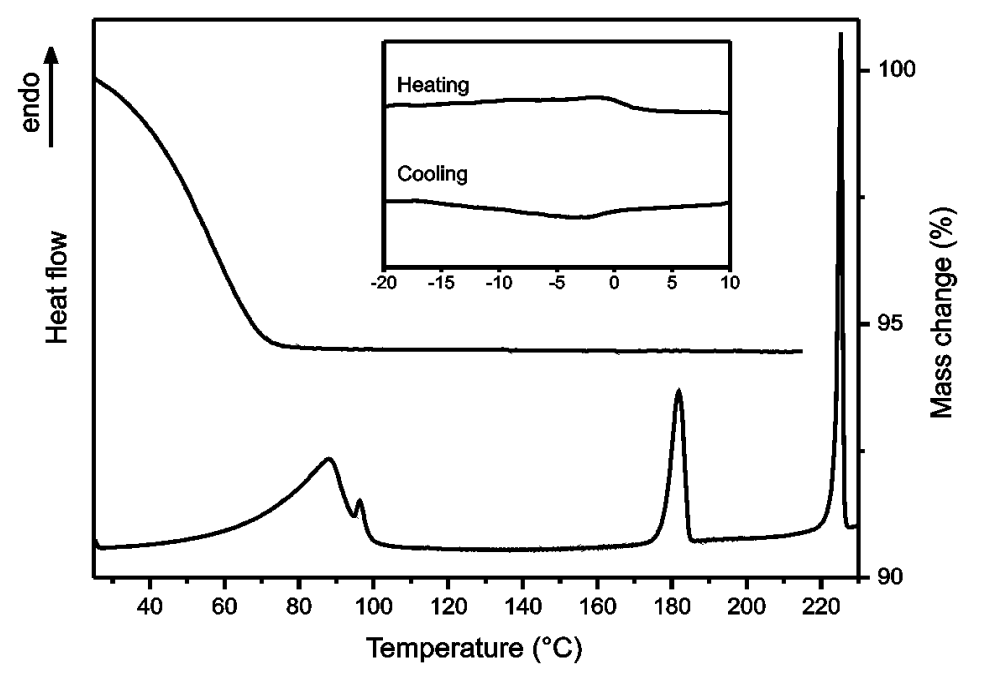

Figure 1. TG (top) and DSC (bottom) thermograms of the room temperature dihydrate with the DSC thermogram of the reversible phase transition to the low temperature dihydrate (insert).

In addition to dehydration by heat, as probed by thermal analysis, hydrate stability against changes in RH are important during pharmaceutical manufacturing. ${ }^{26}$ The dynamic vapor sorption isotherm of HDI dihydrate (Fig. 2) shows its stability between $20 \%$ and $90 \%$ RH, and thus a considerably higher stability against dehydration than can be anticipated from the TG trace, in which dehydration starts already at room temperature. This is likely due to the dry nitrogen purge of the sample that produces an environment of less than 20\% RH. Below $20 \% \mathrm{RH}$, the dihydrate releases the incorporated water in a single step characteristic of stoichiometric hydrates. ${ }^{41}$ Upon sorption up to $50 \% \mathrm{RH}$, the dehydrated crystal form takes up a small amount of water corresponding to surface adsorption. Above 50\% RH, the material takes up two moles of water in a stoichiometric, single-step behavior forming the known room-temperature dihydrate. 


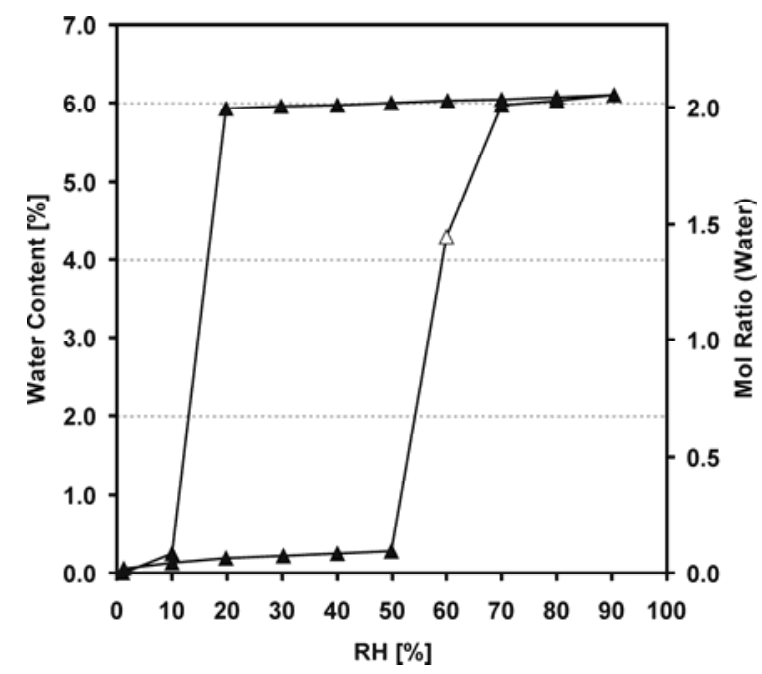

Figure 2. Dynamic moisture sorption-desorption isotherm of the dihydrate at $25^{\circ} \mathrm{C}$ (open symbols not in equilibrium).

The X-ray crystal structures were obtained for both the room-temperature and the lowtemperature form of the dihydrate. In addition, neutron single-crystal diffraction was performed on VIVALDI ${ }^{35}$ at the Institut Laue-Langevin, France, to accurately locate and anisotropically refine the hydrogen atom positions. Neutron data were collected at $290 \mathrm{~K}$ (room-temperature hydrate), $260 \mathrm{~K}$ (low-temperature hydrate) and $20 \mathrm{~K}$ for the most accurate positions and lowest thermal motion. The following structural discussion is based on the structures refined against neutron data.

The room-temperature form crystallizes in the triclinic space group $P-1$ and contains half a molecular unit in the asymmetric unit with the hexamidine on the inversion center. This arrangement arises from co-planarity of the terminal phenyl rings. The structure contains two hydrogen bonded tapes: The tape along [-2 2 -1] contains two hydrogen-bonding motifs between hexamidine and isethionate (Fig. 3a). Each hexamidine interacts through two hydrogen bonds to 
the same isethionate giving a $\mathrm{R}^{2}{ }_{2}(8)$ graph set motif. ${ }^{42}$ Two of these ring motifs form a second centrosymmetric interaction that may be described as $\mathrm{R}^{2} 4(8)$ motif.
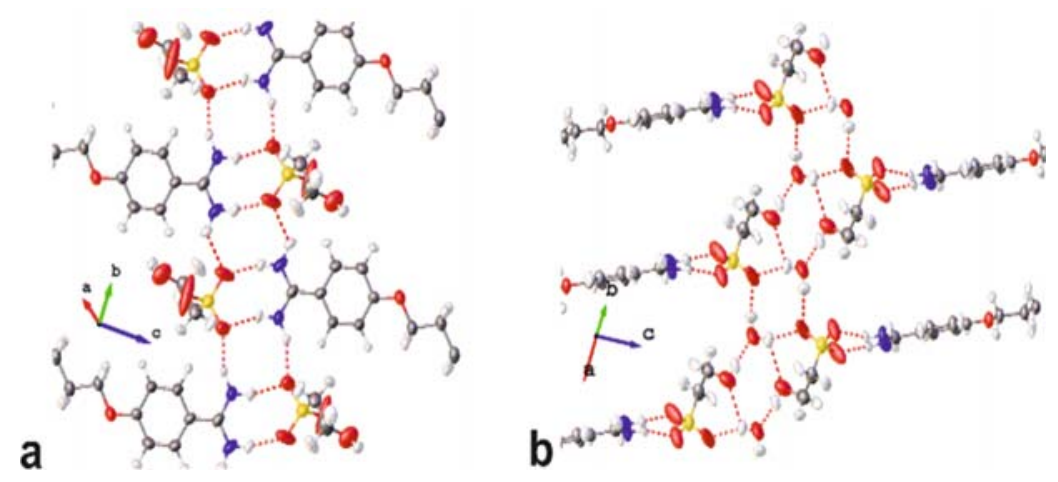

Figure 3. The main intermolecular interactions in the room-temperature dihydrate structure: (a) hexamidine-isethionate tape and (b) isethionate-water tape. Atom coloring: carbon grey, oxygen red, nitrogen blue, sulfur yellow, hydrogen white. Atomic displacement ellipsoids are drawn at $50 \%$ probability based on neutron data.

Almost orthogonal to the first tape and along [ 0 -3 2 $]$ runs the second tape containing interactions between isethionate and water (Fig. 3b). It is noteworthy that there is no direct interaction between the hexamidine cation and the water molecules. The water containing tape is made of two ring motifs, one between two water molecules and the sulfonyl-moieties of two isethionate anions $\left(\mathrm{R}^{2}{ }_{4}(8)\right)$, while the other involves two water molecules and the hydroxyl groups of two isethionate anions $\left(\mathrm{R}_{4}^{4}(8)\right)$. The proximity of both motifs results in bifurcated hydrogen bonds donated through one hydrogen atom of the water molecules.

The overall packing of the room-temperature dihydrate classifies it as an isolated site hydrate, ${ }^{43}$ with the water molecules strongly bound within the hydrogen-bonded network. This type of hydrate is generally stable leading to higher dehydration temperatures due to the lack of open diffusion pathways for the water molecule to leave the structure. ${ }^{2}$ 
The obtained crystal structures were investigated with the partial charges and chemical hardness algorithm PACHA ${ }^{44}$ (Table 1), which allows for the energetic deconstruction of the crystal lattice energy and thus the determination of energetic contribution of specific molecular interactions, e.g. hydrogen bonds. For purposes of quick calculation times, the algorithm treats atoms as point charges and calculates only the electrostatic interactions. The absolute numbers obtained have thus to be taken as indications of magnitude only. However, the ranking of the interactions should not change. In addition, the interactions listed in Table 1 represent only selected strong interactions and are by no means the only stabilizing forces within the respective crystal structures.

The linear interaction between hexamidine and isethionate through two hydrogen bonds is the most stabilizing single motif of the structure and carries over $-30 \mathrm{~kJ} / \mathrm{mol}$ per hydrogen bond, which reflects the charge-assisted nature of this interaction. The two hydrogen bonds along the hexamidine-isethionate tape are $10 \mathrm{~kJ} / \mathrm{mol}$ per bond weaker, even though they are only $0.1 \AA$ longer. Both of these interactions, however, deviate stronger from linearity and show angles between the donor and acceptor group of 158 and $123^{\circ}$, compared to 168 and $159^{\circ}$ for the linear motif. This result emphasizes the importance the geometry of the hydrogen bond has on the strength of this interaction, which is best investigated using the accurate hydrogen atom positions obtained by neutron diffraction. ${ }^{45}$

The water molecules of the room-temperature dihydrate structure is involved in three hydrogen bonds, one accepting and two donating. The interaction donated by the hydroxyl moiety to the water molecule is with an angle of $173^{\circ}$ very direct and with a hydrogen-acceptor distance of $1.79(2) \AA$ is the shortest of the structure. It is thus not surprising that this bond is with over -35 $\mathrm{kJ} / \mathrm{mol}$ the strongest individual interaction in the crystal structure. The two hydrogen bonds donated by the water molecule are with -15 to $-20 \mathrm{~kJ} / \mathrm{mol}$ much weaker individually but add to an 
overall interaction energy of over $-85 \mathrm{~kJ} / \mathrm{mol}$ for the water molecule, which anchors it strongly within the structure.

Table 1. Electrostatic interaction energies of the hydrate neutron crystal structures as calculated by the PACHA algorithm.

\begin{tabular}{llll} 
Hydrogen bond & RT hydrate $(290 \mathrm{~K})$ & LT hydrate $(260 \mathrm{~K})$ & LT hydrate $(20 \mathrm{~K})$ \\
& {$[\mathrm{kJ} / \mathrm{mol}]$} & {$[\mathrm{kJ} / \mathrm{mol}]$} & {$[\mathrm{kJ} / \mathrm{mol}]$} \\
\hline $\mathrm{N}-\mathrm{HN} \cdots \mathrm{O}=\mathrm{S}$ & & -32.8 & -33.5 \\
$($ Amidine H-bond $)$ & -31.6 & -32.7 & -31.3 \\
\hline Orthogonal H-bond & -20.0 & $-23.9^{\mathrm{a}}$ & $-25.1^{\mathrm{a}}$ \\
$\mathrm{N}-\mathrm{HN} \cdots \mathrm{O}=\mathrm{S}$ & -18.5 & $-11.4^{\mathrm{a}}$ & $-16.8^{\mathrm{a}}$ \\
\hline Isethionate & & -28.6 & -24.4 \\
O-H $\cdots \mathrm{OW}$ & -36.3 & -26.8 & -25.3 \\
\hline & & -28.3 & -25.4 \\
OW-H1W $\cdots \mathrm{O}=\mathrm{S}$ & -20.6 & -22.4 & -22.2 \\
& & -16.1 & $-16.1^{\mathrm{c}}$ \\
& & $-15.1^{\mathrm{b}}$ & -19.5 \\
\hline
\end{tabular}

[a] average between two amidine moieties [b] average value for bifurcated hydrogen bond [c] bifurcated between isethionate sulfonyl and hydroxyl oxygen

The structure of the low-temperature dihydrate exists in the triclinic space group $P-1$ and is with a similarity index of 0.985 (as calculated by CSD Mercury) very similar to that of the roomtemperature structure. Small differences can be detected, which are due to the overall shrinking of 
the structure at the lower temperature. During the transition from the room-temperature form, the hexamidine molecule changes conformation from planar to slightly twisted, such that the phenyl rings show a interplanar angle of $2.53(7)^{\circ}$ (Fig S1). This change is most likely due to a 'freezing' of the molecular motion. Due to the non-planarity, the hexamidine cation can no longer lie on the inversion center, which results in doubling of $Z^{\prime}$ from 0.5 in the room-temperature hydrate to 1 in the low-temperature form. In addition to the loss of planarity in the hexamidine molecule, one isethionate anion slightly twists out of the linear hydrogen-bonded dimer, resulting in an elongated, bifurcated hydrogen bond (Fig. 4).

\section{DH RT}

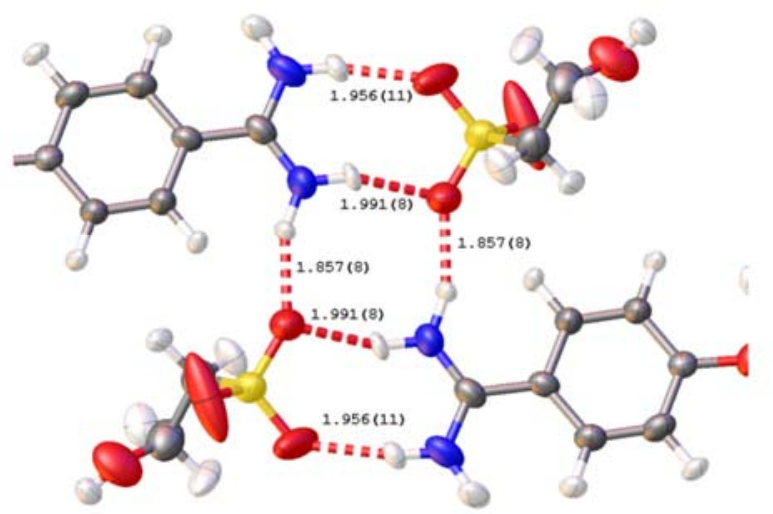

DH LT

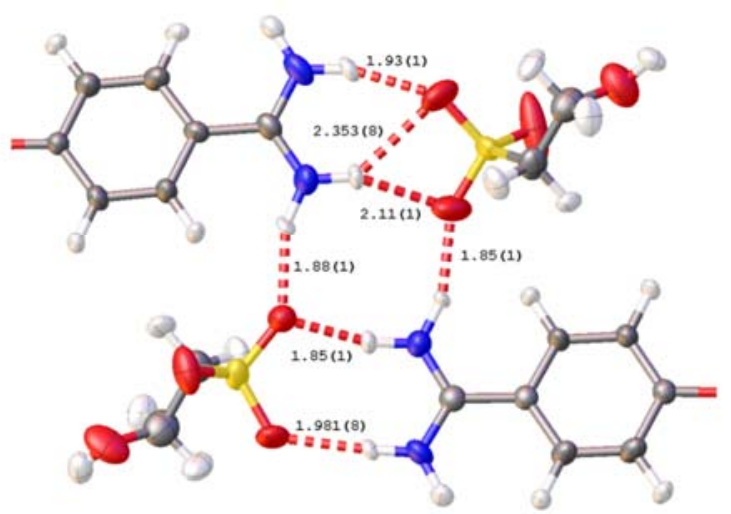

Figure 4. Hydrogen bonding between the hexamidine cation and the isethionate anions in the room-temperature (DH RT) and low-temperature (DH LT) dihydrate crystal structure. Atomic displacement ellipsoids are drawn at $50 \%$ probability based on neutron data.

Although this change generates an additional hydrogen bond, it also destabilizes the existing such that the overall interaction energy of the dimer hardly changes (Table 1). In addition, one of the original orthogonal interactions between amidine and isethionate is made impossible by this rotation, so that a new hydrogen bond is established to the third oxygen atom of the sulfonyl group. This interaction is over $0.1 \AA$ longer than the room-temperature motif and its interaction energy drops by over $7 \mathrm{~kJ} / \mathrm{mol}$. Another result of the twisted isethionate is a bifurcated hydrogen bond 
established between one water molecule and the twisted sulfonyl group. This change strengthens the interaction, which now consists of two hydrogen bonds of medium strength $(-15.1 \mathrm{~kJ} / \mathrm{mol})$ instead of one. Interestingly, the very strong hydrogen bond between the isethionate hydroxyl groups and the water molecules are reduced in energy, which is not a direct result of elongation of these contacts, as both hydrogen bonds are very short with hydrogen-acceptor distances of $1.75(1)$ and 1.86(2) $\AA$. A possible explanation is the stronger interaction of both isethionate anions with the charged amidine groups of the cation and the increased shielding of the negative charge, which reduces the polarization of the hydrogen bond involving the non-charged moiety of the anion.

As expected, cooling of the HDI dihydrate to $20 \mathrm{~K}$ reduces the atomic displacement parameters of the structure considerably. This reduction is particularly pronounced in the isethionate anions and the water molecules, which points towards a higher mobility of these components of the crystal structure at higher temperatures compare to the larger hexamidine cations. In detail, the sulfonate group of the anion shows considerable rotational motion in the higher temperature structures but is completely ordered at $20 \mathrm{~K}$, and its resting orientation is not at the motional center of the hightemperature ADP ellipsoids (Fig. S2). Connected to this ordering, the water molecule changes orientation slightly. While none of these structural differences change the packing motif or the hydrogen-bonding network, they influence the related energies of the strong molecular interactions. The most significant change in interaction energy relates to the hydrogen bond between the water and the sulfonate group. Due to the slightly off-center orientation of the accepting group, the interaction $\mathrm{OW}-\mathrm{H} 2 \mathrm{~W} \cdots \mathrm{O}=\mathrm{S}$ changes from a bifurcated hydrogen bond to a single and more directional interaction. This strengthens the interaction energy by more than -4 $\mathrm{kJ} / \mathrm{mol}$. This same ordering effects a weaker interaction in the second water-isethionate pair, which destabilizes the structure by approximately $+3 \mathrm{~kJ} / \mathrm{mol}$. The overall lower thermal vibration also 
causes the angle of the hydrogen bond from the isethionate OH-group to the accepting water to become more acute $\left(173(3) / 169(2)^{\circ}\right.$ at $260 \mathrm{~K}$ vs. $171.6(7) / 163.6(8){ }^{\circ}$ at $\left.20 \mathrm{~K}\right)$, which can again be seen by an increase of interaction energy by $+4 \mathrm{~kJ} / \mathrm{mol}$. Finally, the orthogonal hydrogen bonds in the amidine-isethionate tapes become more stabilizing due to a reduction of the interaction distance (H-A distance 1.85(1), 1.88(1), 2.00(1) and 2.30(1) $\AA$ at $260 \mathrm{~K}$ vs. 1.870(6), 1.881(6), 1.934(6) and $1.938(6) \AA$ at $20 \mathrm{~K})$. It is thus clear that not only the relative arrangement of the interacting molecules plays a major role in the strength of molecular interactions within crystal structure, but the thermal motion of the interacting groups does as well. In addition, since the final orientation of the sulfonate group is unexpected, it is important to measure the crystal structure at the lowest temperature possible to obtain accurate interaction energies.

\section{Anhydrous polymorphs}

HDI crystallizes spontaneously into form A (Fig. 5a, Fig. S3) when the super-cooled melt, or amorphous glass, is heated above the glass-transition point of approximately $60{ }^{\circ} \mathrm{C}$. This metastable form presents with a platy habit and transforms to form $\mathrm{B}$ between $70{ }^{\circ} \mathrm{C}$ and $110{ }^{\circ} \mathrm{C}$ with an exothermic event (Fig. 6), which is not reversible upon cooling and thus a clear indication of the monotropic relationship of forms A and B. Form B can also be obtained by dehydration of the room temperature dihydrate. Upon heating above $170{ }^{\circ} \mathrm{C}$, form $\mathrm{B}$ transforms into form $\mathrm{C}$, which is the high-temperature polymorph of this system. Further heating leads to melting of form $\mathrm{C}$ at $224{ }^{\circ} \mathrm{C}$.
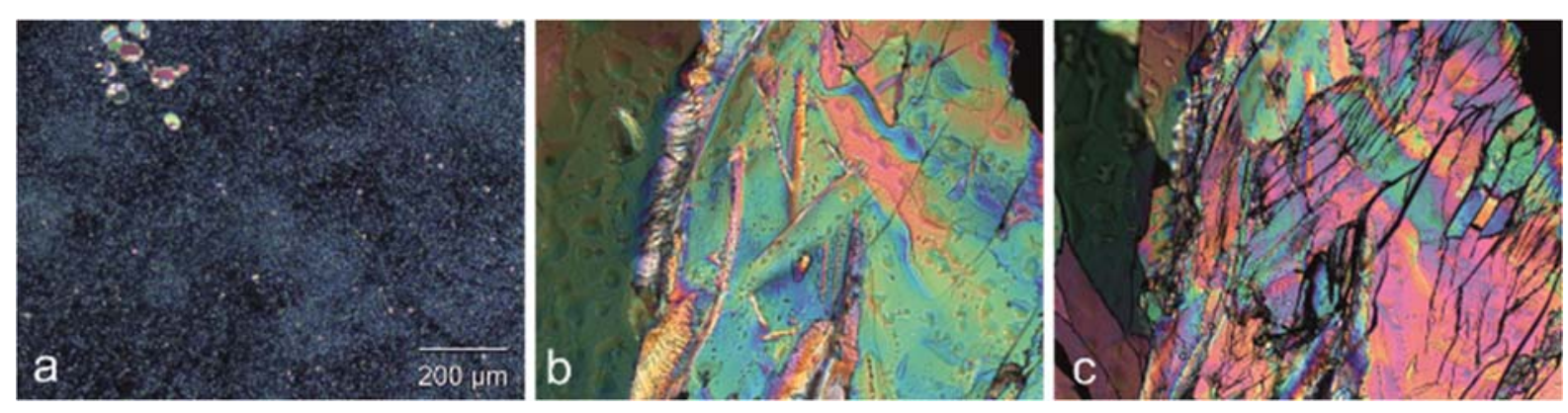
Figure 5. Photomicrographs of a) form A during spontaneous nucleation from the melt at $60{ }^{\circ} \mathrm{C}$, b) melt-film preparation of form $\mathrm{H}$ at $100{ }^{\circ} \mathrm{C}$ and c) same melt-film after transition to form I at room temperature.
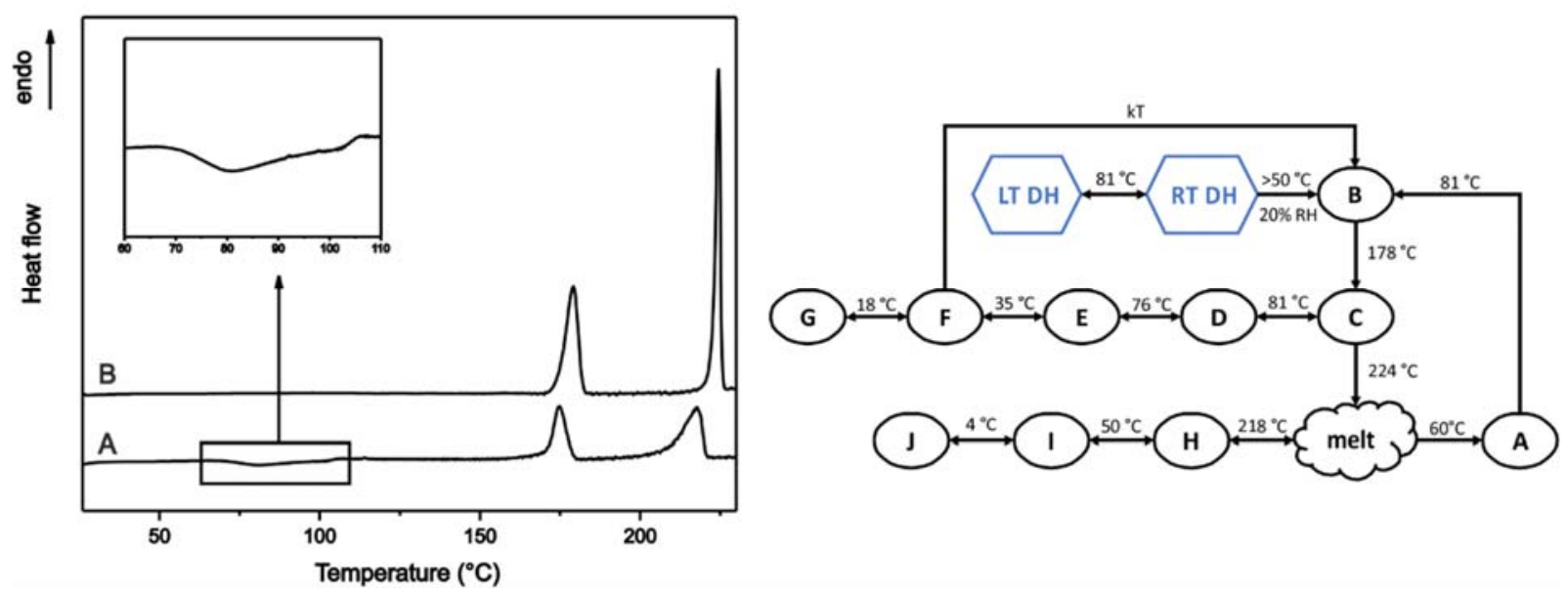

Figure 6. DSC thermograms starting from HDI forms A and B (left), and polymorphism scheme with transition pathways of HDI (right).

Surprisingly, upon cooling of the high-temperature form C, the reverse transition to form B is not observed but instead a new series of anhydrous polymorphs appear with sequential transition points (Fig. 7 left). The first transition upon cooling (C -> D) occurs as very small exotherm between 160 and $140{ }^{\circ} \mathrm{C}$, followed by a larger exotherm between 50 and $40{ }^{\circ} \mathrm{C}$ (D -> E), a very shallow exotherm between 30 and $20^{\circ} \mathrm{C}(\mathrm{E}->\mathrm{F})$ and the final larger and sharper exotherm between 14 and $8{ }^{\circ} \mathrm{C}(\mathrm{F}->\mathrm{G})$. Due to their reversibility, all of these events can be detected as endotherms in the respective heating curve between 20 and $30{ }^{\circ} \mathrm{C}(\mathrm{G}->\mathrm{F}), 37$ and $50{ }^{\circ} \mathrm{C}(\mathrm{F}->\mathrm{E}), 75$ and 81 ${ }^{\circ} \mathrm{C}(\mathrm{E}->\mathrm{D})$ and 130 and $140{ }^{\circ} \mathrm{C}(\mathrm{D}->\mathrm{C})$. 

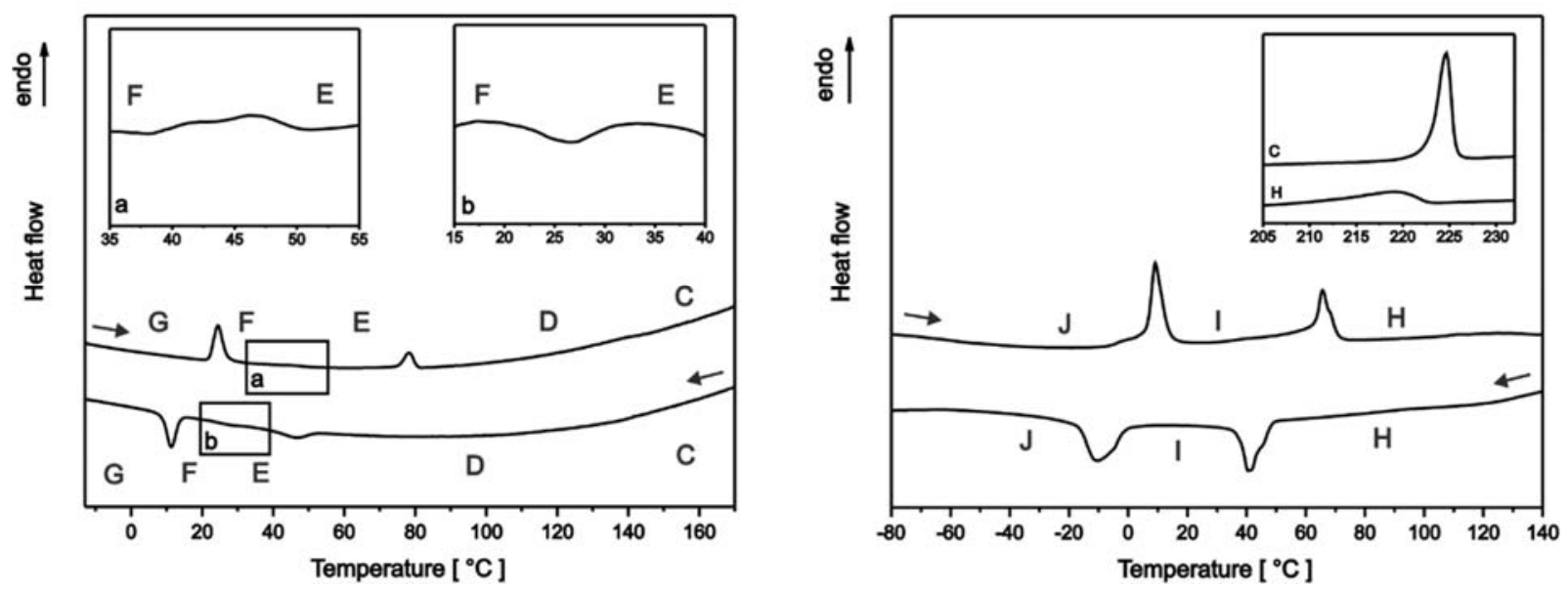

Figure 7. DSC thermograms of the heating/cooling program starting from form $\mathrm{C}$ (left) with the transition of E -> F (a) and F -> E (b) as inserts, and form $\mathrm{H}$ (right) with comparison of the melting endotherms of forms $\mathrm{C}$ and $\mathrm{H}$ as insert.

The existence of all forms in the thermal cycle starting with form $\mathrm{C}$ could be proven by variabletemperature PXRD measurements (Fig. 8a, Fig. S4). The starting sample consisted of form F with traces of form B impurity, as seen by the two peaks at around $12^{\circ} 2 \theta$. These vanish completely when the sample is heated to $170{ }^{\circ} \mathrm{C}$, the transition point of form $\mathrm{B}$ to form $\mathrm{C}$. Upon heating, the peaks of form $\mathrm{F}$ show a strong anisotropic shift in position up to the transition temperature between 50 and $55^{\circ} \mathrm{C}$, with some peaks shifting to the expected lower angles (e.g. peak at $16.4^{\circ}$ and at $16.6^{\circ}$ 20). A clear phase transition can only be observed at $75^{\circ} \mathrm{C}$ representing the transition from form E to form D. However, plotting the peak positions over temperature, subtle changes in the thermal behavior of the peak shifts can be observed (Fig. $8 \mathrm{~b}$ and c), which correlate well with the transition points detected by DSC. It is clear from the DSC thermograms that these phase transitions are firstorder transitions with a small but significant transition enthalpy; however, it is rare to detect transitions as changes in diffraction peak-shift behavior only and not accompanied by a more substantial change in diffraction patterns. It may well be that the phase transitions resemble order- 
disorder transitions, in which parts of the molecules will increase thermal motion upon heating until the activation energy for a conformational change is overcome. This change is generally accompanied by a change in physicochemical characteristics, as has been shown for the dielectric constant $^{46}$ or magnetic moment, ${ }^{47}$ and leads to a breaking of the crystal symmetry with accompanied emergence of new peaks. Since no new peaks appear upon cooling in the case of HDI, it is likely that the crystal forms have already the lowest symmetry. To prove this, though, the crystal structures of these polymorphic forms are necessary, which is in the scope of ongoing investigations.
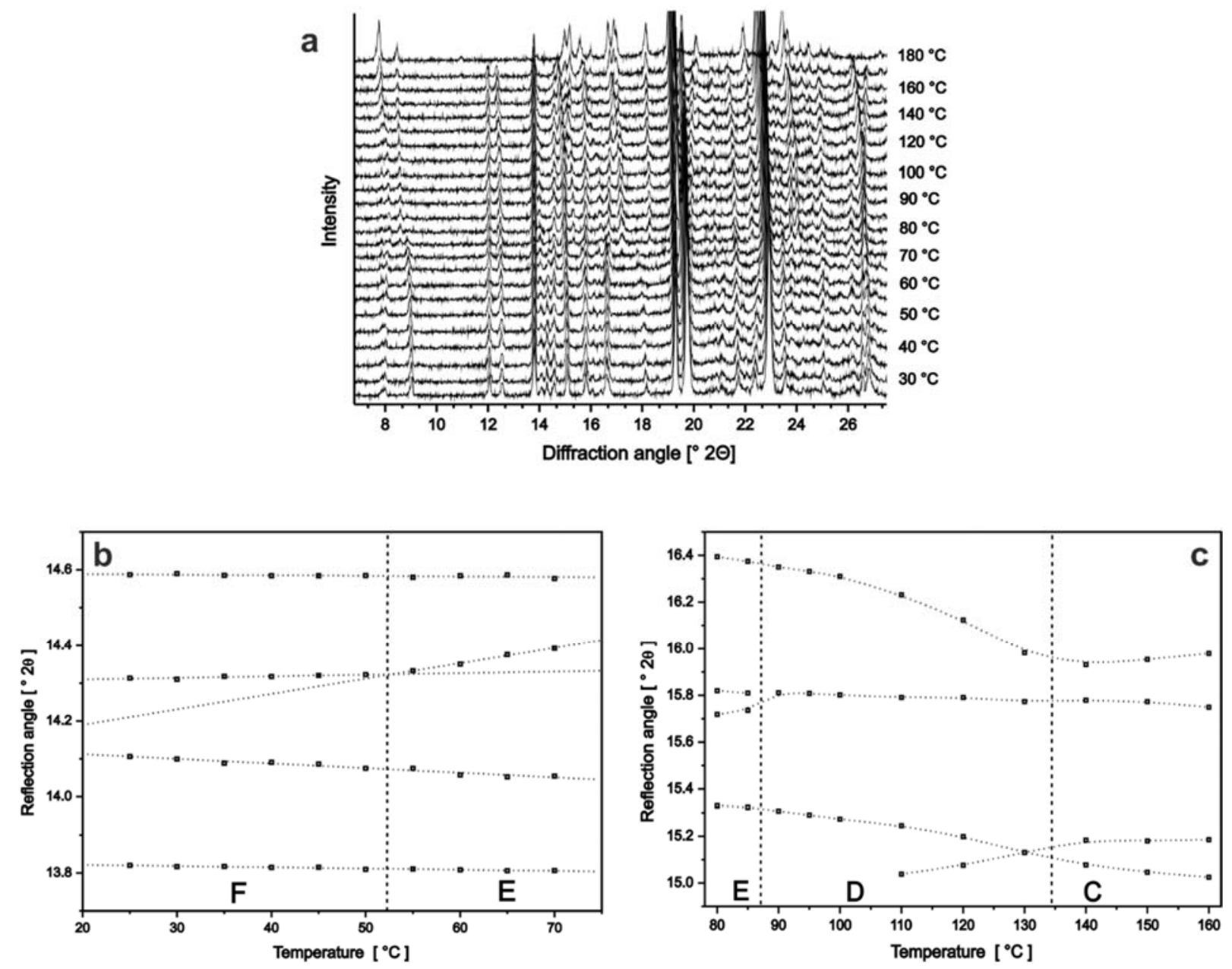
Figure 8. Variable-temperature PXRD patterns starting from HDI form $F$ (a) and the representation of peak positions over temperature during the heating cycle of the same measurement, (b) presenting the phase transition of form $\mathrm{F}$ to $\mathrm{E}$ and (c) from form $\mathrm{E}$ to $\mathrm{D}$ and further to $\mathrm{C}$.

In addition to the low-temperature form A, a second polymorph can be directly crystallized from the melt at high temperature (Fig. 5b). This crystal form $\mathrm{H}$ is different to the high-temperature form $\mathrm{C}$ and shows a second series of sequential transformations upon cooling. The first transition to form I occurs between 50 and $35{ }^{\circ} \mathrm{C}$ and is accompanied by a pronounced cracking of the melt film preparation to the extent that the cover slip lifts off the preparation (ESI video). This points towards very different crystal packing of these two polymorphs. A second and less violent transition can be detected between 0 and $-17^{\circ} \mathrm{C}$ and represents the change from form I to form $\mathrm{J}$. As in the cycle for form $\mathrm{C}$, these two transitions are highly reversible and can be detected as respective endothermic events upon heating between 8 and $15{ }^{\circ} \mathrm{C}(\mathrm{J}->\mathrm{I})$ and 60 and $73{ }^{\circ} \mathrm{C}(\mathrm{I}->$ H). Since both transitions are much more pronounced than those in the thermal cycle starting from form C, only PXRD patterns well within the thermal stability range of the crystal forms have been recorded (Fig. S5). It is surprising that the pattern of form $\mathrm{H}$ shows close resemblance to form B, but contamination with form $\mathrm{B}$ can be excluded as the pattern of form $\mathrm{H}$ was recorded at a temperature that is outside its stability range.

With the thermodynamic data extracted from the DSC thermograms (table S2), it was possible to construct a semi-schematic energy-temperature diagram for HDI based on the heat of fusion and the heat of transition rules established by Burger and Ramberger (Fig. 9). ${ }^{48,49}$ This diagram depicts schematically the Gibb's free energy $G$ and the enthalpy $H$ over temperature of each polymorph along with those of the melt. In the case of two polymorphs having $G$-isobars 
intercrossing at a temperature below the melting point, this pair is enantiotropically related with a transition point at the crossing. If two polymorphs have $G$-isotherms converging but not crossing before intersecting with the liquid, they are monotropically related and the crystal form with the lower lying $G$-isotherm is the more stable form at all temperatures. The intersection of the $G$ isotherm of any polymorph with that of the liquid represents the melting point. This diagram thus visualizes the relationships of polymorphic pairs even when their transitions cannot be observed.

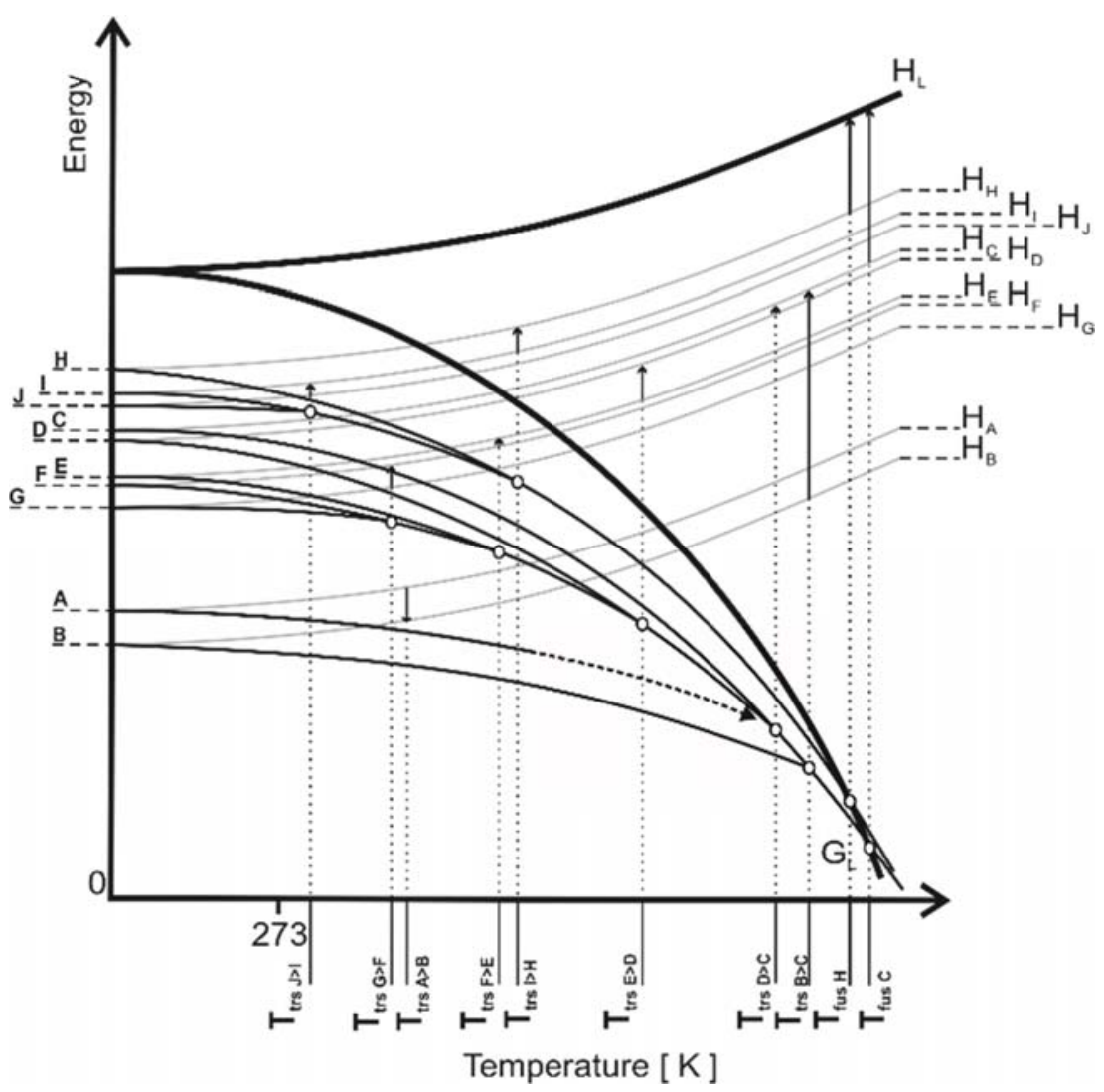

Figure 9. Semi-schematic energy-temperature diagram of the ten polymorphs of HDI.

The diagram for HDI highlights the complexity of the polymorphic system based on the ten observed polymorphs giving rise to 45 polymorphic transitions. In the case of HDI, the nature of most of these transitions cannot be resolved due to the lack of melting points. However, it is quite 
clear that form B is the thermodynamically stable crystal form up to its transition to the high temperature form $\mathrm{C}$, which then is the most stable form until melting. The diagram also shows that the crystal forms within the two cycles C, D, E, F, G and H, I, J are enantiotropically related to each other, while the $G$-isotherm of their respective most stable forms run on parallel at all temperatures indicating that the relationships of the crystal forms different cycles are monotropic. Surprisingly, the metastable form A, which can only be crystallized from the super-cooled melt and transforms quickly into form $\mathrm{B}$, is in fact more stable than most of the other crystal forms of the system. The absolute stability ranking of the crystal forms, as extrapolated from the $G$ - and $H$ isotherms at $0 \mathrm{~K}$, is $\mathrm{B}>\mathrm{A}>\mathrm{G}>\mathrm{F}>\mathrm{E}>\mathrm{D}>\mathrm{C}>\mathrm{J}>\mathrm{I}>\mathrm{H}$.

It was possible to solve the crystal structure of the stable crystal form B from X-ray powder diffraction data (Fig. S6). The structure exists in the space group $C 2 / c, Z=8$ with half a molecular unit in the asymmetric unit. The hexamidine cations adopt an elongated, nearly planar conformation, and arrange in a staggered stacking in which only half of the molecule overlaps with the one in the next layer. The isethionate anions are located in between these cation stacks, each anion disordered over two positions with 0.74 and 0.26 occupancy, respectively. The molecular interactions between hexamidine and isethionate are comparable to those observed in the dihydrates with two hydrogen bonds linearly between the guanidine moiety and the sulfonate either on parallel or through a bifurcated interaction. A second hydrogen bond is donated to the next isethionate generating infinite hydrogen-bonded chains as in the hydrates (Fig 3a). However, the isethionate anions of form B are oriented along the same plane as the hexamidine, not orthogonal as in the hydrates, and thus two of them fill pockets between two hexamidine cations in the same layer. With the water molecules missing to bridge between the isethionate anions involving their hydroxyl moieties, the anions 'rattle' in this space and show disorder. Another factor for the 
disorder is the hydrogen bonding realized through the two different orientations of the sulfonate moiety (Fig S7). One orientation can form two hydrogen bonds through short distances with the amidine moiety in the linear chains with donor-acceptor distance of 2.5(3) $\AA$ and donor-hydrogenacceptor angle of $179^{\circ}$ for one and 3.0(3) $\AA$ and $167^{\circ}$ for the other. This strong interaction is realized as trade-off with only longer and less direct hydrogen bonds orthogonally to the chains, 2.7(3) $\AA$ and $159^{\circ}$ for one, 3.1(3) $\AA$ and $134^{\circ}$ for the other. The second orientation leads to a more direct interaction in the orthogonal direction with $2.5(3) \AA$ and $137^{\circ}$ for one and 2.7(3) $\AA$ and $154^{\circ}$ for the other hydrogen bond, which can only be realized by a longer distance in the linear interaction (3.3(3) $\AA$ and $156^{\circ}, 3.7(3) \AA$ and $\left.156^{\circ}\right)$.

\section{Conclusion}

Hexamidine diisethionate exists in at least two polymorphic dihydrates and ten anhydrous polymorphs. The dihydrate undergoes a fully reversible phase transition at low temperature, which is accompanied by the freezing of the vibrational motion of the cation resulting in the doubling of a unit cell axis. This phase transition results in small but significant changes in the hydrogenbonding pattern, and their respective interaction energies. Of the anhydrous polymorphs of HDI, the dehydrate form $\mathrm{B}$ is the thermodynamically stable form at temperatures below its transition point to form $\mathrm{C}$. The remaining polymorphs are accessible from the high-temperature forms $\mathrm{C}$ or $\mathrm{H}$ in sequential and highly reversible phase transitions. Following these transitions by variabletemperature PXRD shows that several phase changes are not accompanied by significant structural changes but can only be detected as change in the thermally induced peak shifts. This rare behavior points towards a border case between first- and second-order phase transition, in which the molecules undergo a change in vibrational motion rather than a restructuring of the crystal architecture. However, thermal data shows clear characteristics of a first-order phase transition. It 
is likely that the strong charge-assisted hydrogen bonds between the anions and the cationic end groups of hexamidine anchor the overall packing motif, while the large, flexible and apolar hexylene linker of the hexamidine molecules can adopt different conformations due to the lack of strong interactions. With this, HDI resembles thermotropic liquid crystals and lipids. However, to unambiguously determine the process of these phase transitions, structural data are required of all polymorphs, which is the scope of ongoing investigations.

The complex solid-state behavior of HDI offers a rare opportunity to study sequential phase transitions in an organic molecule. The impact on manufacture of the drug compound will be minimal due to the clear stability of the dihydrate and form B; however, this study highlights that only the application of a suitably wide variety of analytical methods can give a holistic understanding of a solid-state system. It is particularly important to combine thermal analysis with structural data, e.g. from variable-temperature PXRD. While the determination of a crystal structure is important and will give essential information, this structure only gives a static picture at a defined temperature and information about the dynamic behavior is not revealed in many studies. 


\section{Supporting Information.}

Crystal structures of the HDI hydrates (1950790 - 1950794) and of the anhydrous form B (1949968) can be accessed free of charge from the Cambridge Crystallographic Data Center (https://www.ccdc.cam.ac.uk/structures/).

The following files are available free of charge.

Additional figures and data to the manuscript (PDF)

Video of the phase transition of form $\mathrm{H}$ to form I (AVI)

\section{Corresponding Author}

* Katharina Edkins, k.edkins@qub.ac.uk

\section{Present Addresses}

${ }^{\$}$ Garry J. McIntyre: Australian Nuclear Science and Technology Organisation, Lucas Heights, NSW 2234, Australia

Daniel Többens: Helmholtz-Zentrum Berlin für Materialien und Energie, Hahn-Meitner Platz 1, 14109 Berlin, Germany

$\dagger$ deceased

\section{ACKNOWLEDGMENT}

We thank the Institut Laue-Langevin for beamtime allocation through proposal 5-12-226. KE and JWS thank EPSRC for funding (EP/F063229/1)

\section{REFERENCES}

(1) Mitscherlich, E., Sur la relation qui existe entre la forme cristalline et les proportions chimiques, I. Mémoire sure les arseniates et les phosphates. Ann. Chim. Phys. 1822, 19, 350-419. (2) Brittain, H. G., Polymorphism in Pharmaceutical Solids. ed.; Marcel Dekker Inc.: New York, 1999. 
(3) Bernstein, J., Polymorphism in Molecular Crystals. ed.; Clarendon Press: Oxford, 2002. (4) Lee, A. Y.; Erdemir, D.; Myerson, A. S., Crystal Polymorphism in Chemical Process Development. Annu. Rev, Chem. Biomol. 2011, 2, (1), 259-280.

(5) Chemburkar, S. R.; Bauer, J.; Deming, K.; Spiwek, H.; Patel, K.; Morris, J.; Henry, R.; Spanton, S.; Dziki, W.; Porter, W.; Quick, J.; Bauer, P.; Donaubauer, J.; Narayanan, B. A.; Soldani, M.; Riley, D.; McFarland, K., Dealing with the Impact of Ritonavir Polymorphs on the Late Stages of Bulk Drug Process Development. Org. Process Res. Dev. 2000, 4, (5), 413-417.

(6) Bauer, J.; Spanton, S.; Henry, R.; Quick, J.; Dziki, W.; Porter, W.; Morris, J., Ritonavir: an extraordinary example of conformational polymorphism. Pharm Res 2001, 18, (6), 859-66.

(7) Morissette, S. L.; Soukasene, S.; Levinson, D.; Cima, M. J.; Almarsson, O., Elucidation of crystal form diversity of the HIV protease inhibitor ritonavir by high-throughput crystallization. Proc Natl Acad Sci U S A 2003, 100, (5), 2180-4.

(8) Rietveld, I. B.; Ceolin, R., Rotigotine: Unexpected Polymorphism with Predictable Overall Monotropic Behavior. J. Pharm. Sci. 2015, 104, (12), 4117-4122.

(9) Tan, M.; Shtukenberg, A. G.; Zhu, S.; Xu, W.; Dooryhee, E.; Nichols, Shane M.; Ward, M. D.; Kahr, B.; Zhu, Q., ROY revisited, again: the eighth solved structure. Faraday Discussions 2018, 211, (0), 477-491.

(10) Gushurst, K. S.; Nyman, J.; Boerrigter, S. X. M., The PO13 crystal structure of ROY. CrystEngComm 2019, 21, (9), 1363-1368.

(11) Foster, J. A.; Damodaran, K. K.; Maurin, A.; Day, G. M.; Thompson, H. P. G.; Cameron, G. J.; Bernal, J. C.; Steed, J. W., Pharmaceutical polymorph control in a drug-mimetic supramolecular gel. Chem. Sci. 2017, 8, (1), 78-84.

(12) Falk, J.; Hofmann, D.; Merz, K., Controlled usage of H/D exchange to circumvent concomitant polymorphs of ROY. IUCrJ 2018, 5, (5), 569-573.

(13) Nyman, J.; Yu, L.; Reutzel-Edens, S. M., Accuracy and reproducibility in crystal structure prediction: the curious case of ROY. CrystEngComm 2019, 21, (13), 2080-2088.

(14) Thomas, S. P.; Spackman, M. A., The Polymorphs of ROY: A Computational Study of Lattice Energies and Conformational Energy Differences. Aust. J. Chem. 2018, 71, (4), 279-284. (15) Sugden, I.; Adjiman, C. S.; Pantelides, C. C., Accurate and efficient representation of intramolecular energy in ab initio generation of crystal structures. I. Adaptive local approximate models. Acta Crystallogr. B 2016, 72, 864-874.

(16) Tessler, L.; Goldberg, I., Crystal Structures of Aripiprazole, a New Anti-psychotic Drug, and of its Inclusion Compounds with Methanol, Ethanol and Water. J. Incl. Phen. Macro. 2006, $55,(3), 255-261$.

(17) Braun, D. E.; Gelbrich, T.; Kahlenberg, V.; Tessadri, R.; Wieser, J.; Griesser, U. J., Conformational polymorphism in aripiprazole: Preparation, stability and structure of five modifications. J. Pharm. Sci. 2009, 98, (6), 2010-2026.

(18) Delaney, S. P.; Smith, T. M.; Pan, D.; Yin, S. X.; Korter, T. M., Low-Temperature Phase Transition in Crystalline Aripiprazole Leads to an Eighth Polymorph. Cryst. Growth Des. 2014, 14, (10), 5004-5010.

(19) Zencirci, N.; Griesser, U. J.; Gelbrich, T.; Apperley, D. C.; Harris, R. K., Crystal Polymorphs of Barbital: News about a Classic Polymorphic System. Mol. Pharm. 2014, 11, (1), 338-350.

(20) Zencirci, N.; Gelbrich, T.; Kahlenberg, V.; Griesser, U. J., Crystallization of Metastable Polymorphs of Phenobarbital by Isomorphic Seeding. Cryst. Growth Des. 2009, 9, (8), 34443456. 
(21) Zencirci, N.; Gelbrich, T.; Apperley, D. C.; Harris, R. K.; Kahlenberg, V.; Griesser, U. J., Structural Features, Phase Relationships and Transformation Behavior of the Polymorphs I-VI of Phenobarbital. Cryst. Growth Des. 2010, 10, (1), 302-313.

(22) Braun, D. E.; Gelbrich, T.; Kahlenberg, V.; Tessadri, R.; Wieser, J.; Griesser, U. J., Stability of Solvates and Packing Systematics of Nine Crystal Forms of the Antipsychotic Drug Aripiprazole. Cryst. Growth Des. 2009, 9, (2), 1054-1065.

(23) Kons, A.; Bērziņš, A.; Actiňš, A.; Rekis, T.; van Smaalen, S.; Mishnev, A., Polymorphism of R-Encenicline Hydrochloride: Access to the Highest Number of Structurally Characterized Polymorphs Using Desolvation of Various Solvates. Cryst. Growth Des. 2019.

(24) Bhardwaj, R. M.; McMahon, J. A.; Nyman, J.; Price, L. S.; Konar, S.; Oswald, I. D. H.; Pulham, C. R.; Price, S. L.; Reutzel-Edens, S. M., A Prolific Solvate Former, Galunisertib, Under the Pressure of Crystal Structure Prediction, Produces Ten Diverse Polymorphs. J. Am. Chem. Soc. 2019.

(25) ICH guideline Q3C

(26) Khankari, R. K.; Grant, D. J. W., Pharmaceutical hydrates. Thermochim. Acta 1995, 248, (0), 61-79.

(27) Fucke, K.; McIntyre, G. J.; Lemée-Cailleau, M.-H.; Wilkinson, C.; Edwards, A. J.; Howard, J. A. K.; Steed, J. W., Insights into the Crystallisation Process from Anhydrous, Hydrated and Solvated Crystal Forms of Diatrizoic Acid. Chem. Eur. J. 2015, 21, (3), 10361047.

(28) Najib, M. N. M.; Back, K.; Edkins, K., The Complex Solid-State Landscape of Sodium Diatrizoate Hydrates. Chem. Eur. J. 2017, 23, (68), 17339-17347.

(29) Fucke, K.; Anderson, K. M.; Filby, M. H.; Henry, M.; Wright, J.; Mason, S. A.; Gutmann, M. J.; Barbour, L. J.; Oliver, C.; Coleman, A. W.; Atwood, J. L.; Howard, J. A. K.; Steed, J. W., The Structure of Water in p-Sulfonatocalix 4 arene. Chem. Eur. J. 2011, 17, (37), 10259-71.

(30) Fucke, K.; McIntyre, G. J.; Wilkinson, C.; Henry, M.; Howard, J. A. K.; Steed, J. W., New Insights into an Old Molecule: Interaction Energies of Theophylline Crystal Forms. Cryst. Growth Des. 2012, 12, (3), 1395-1401.

(31) Fucke, K.; Edwards, A. J.; Probert, M. R.; Tallentire, S. E.; Howard, J. A. K.; Steed, J. W., Unexpected Low-Temperature Behaviour of Piroxicam Monohydrate. ChemPhysChem 2013, 14, (4), 675-679.

(32) David, W. I.; Shankland, K.; Van De Streek, J.; Pidcock, E.; Motherwell, W. S.; Cole, J. C., DASH: a program for crystal structure determination from powder diffraction data. J. Appl. Crystallogr. 2006, 39, (6), 910-915.

(33) Coelho, A. A., TOPAS and TOPAS-Academic: an optimization program integrating computer algebra and crystallographic objects written in C++. J. Appl. Crystallogr. 2018, 51, (1), 210-218.

(34) Dolomanov, O. V.; Bourhis, L. J.; Gildea, R. J.; Howard, J. A. K.; Puschmann, H., OLEX2: a complete structure solution, refinement and analysis program. J. Appl. Crystallogr. 2009, 42, 339-341.

(35) Wilkinson, C.; Cowan, J. A.; Myles, D. A. A.; Cipriani, F.; McIntyre, G. J., VIVALDI A thermal-neutron Laue diffractometer for physics, chemistry and materials science Neutron News 2002, 13, 37-41.

(36) McIntyre, G. J.; Lemée-Cailleau, M.-H.; Wilkinson, C., High-speed neutron Laue diffraction comes of age. Physica B 2006, 385, 1055-1058. 
(37) Campbell, J. W., LAUEGEN, an X-Windows-based Program for the Processing of Laue X-ray-Diffracion Data. J. Appl. Crystallogr. 1995, 28, 228-236.

(38) Campbell, J. W.; Hao, Q.; Harding, M. M.; Nguti, N. D.; Wilkinson, C., LAUEGEN version 6.0 and INTLDM. J. Appl. Crystallogr. 1998, 31, 496-502.

(39) Wilkinson, C.; Khamis, H. W.; Stansfield, R. F. D.; McIntyre, G. J., Integration of Single-Crystal Reflections using Area Multidetectors. J. Appl. Crystallogr. 1988, 21, 471-478.

(40) Sheldrick, G. M., A short history of SHELX. Acta Crystallogr. A 2008, A64, (1), 112 -

122.

(41) Griesser, U. J., The importance of solvates. In Polymorphism, Hilfiker, R., Ed. WileyVCH: Weinheim, Germany, 2006; pp 211-233.

(42) Bernstein, J.; Davis, R. E.; Shimoni, L.; Chang, N.-L., Patterns in Hydrogen Bonding: Functionality and Graph Set Analysis in Crystals. Angew. Chem. Int. Ed. 1995, 34, (15), 15551573.

(43) Morris, K. R., Structural aspects of hydrates and solvates. In Polymorphism in Pharmaceutical Solids, Brittain, H. G., Ed. Marcel Dekker Ltd: New York, 1999; Vol. 95, pp 125-181.

(44) Henry, M., Nonempirical quantification of molecular interactions in supramolecular assemblies. ChemPhysChem 2002, 3, (7), 561-569.

(45) Jeffrey, G. A., An Introduction to Hydrogen Bonding. 1st ed.; OUP: Oxford, 1997.

(46) Han, S.; Liu, X.; Zhang, J.; Ji, C.; Wu, Z.; Tao, K.; Wang, Y.; Sun, Z.; Luo, J., Dielectric phase transition triggered by the order-disorder transformation of cyclopropylamine in a layered organic-inorganic halide perovskite. J. Mater. Chem. C 2018, 6, (38), 10327-10331.

(47) Yadav, R.; Swain, D.; Bhat, H. L.; Elizabeth, S., Order-disorder phase transition and multiferroic behaviour in a metal organic framework compound $(\mathrm{CH} 3) 2 \mathrm{NH} 2 \mathrm{Co}(\mathrm{HCOO}) 3 . J$. Appl. Phys. 2016, 119, (6), 064103.

(48) Burger, A.; Ramberger, R., On the polymorphism of pharmaceuticals and other molecular crystals. I. Theory of thermodynamic rules. Mikrochim. Acta 1979, 2, (3-4), 259-71.

(49) Burger, A.; Ramberger, R., On the polymorphism of pharmaceuticals and other molecular crystals. II. Applicability of thermodynamic rules. Mikrochim. Acta 1979, 2, (3-4), 273-316. 


\section{Table of Contents graphic}

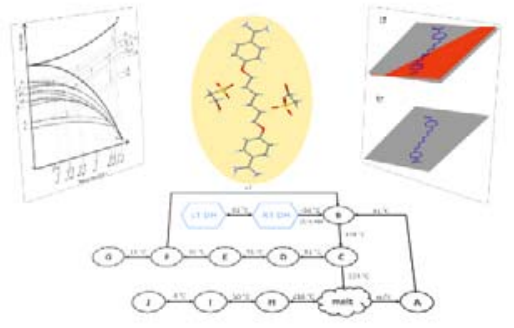

Synopsis: The antiseptic hexamidine diisethionate exists in ten anhydrous polymorphs and a dimorphic dihydrate with highly reversible phase transitions between the crystal forms. Most transitions occur with minor structural changes but clear first-order character. This compound presents a model case for numerous polymorphs, their energetic relationship and their structural changes upon transition. 